\title{
Crosslinking: an updated and effective insight
}

\section{Cross-linking: uma visão objetiva e atualizada}

Roberto Novaes Campello Horovitz'1, Renato Garcia², Samir Jacob Bechara ${ }^{3}$

\begin{abstract}
The corneal cross-linking has been used in order to reduce and stabilize the progression of ectatic diseases through its effects on the biomechanics of the cornea. Different protocols are being conducted worldwide to expand its indications as well as its use at different ages, different stages of the disease, combinations with other techniques, besides the utilization for non-ectatic diseases. There is still no consensus on the indications of the cross-linking procedure, but the results published in the literature show significant changes in the properties of the corneal tissue. The aim of this study is to review some of these protocols already published and discuss their results, indications and complications.
\end{abstract}

Keywords: Keratoconus; Riboflavin; Ultraviolet therapy; Cornea

\section{RESUMO}

O cross-linking corneano é utilizado com o objetivo de reduzir e estabilizar a progressão das patologias ectásicas através de seus efeitos na biomecânica da córnea. Diferentes protocolos estão sendo realizados pelo mundo para expandir suas indicações, assim como seu uso em diversas faixas etárias, diferentes estágios da doença, combinações com outras técnicas, além de utilizações para doenças não ectásicas. Não há ainda um consenso nas indicações do procedimento de cross-linking, mas os resultados publicados na literatura evidenciam mudanças significativas nas propriedades do tecido corneano. O objetivo desse estudo é revisar alguns desses protocolos já publicados e discutir seus resultados, indicações e complicações.

Descritores: Ceratocone; Riboflavina; Terapia ultravioleta; Córnea

\footnotetext{
1,2Faculdade de Medicina da Universidade de São Paulo (FMRP/USP) - São Paulo (SP), Brasil;

${ }^{3}$ Hospital das Clínicas da Faculdade de Medicina da Universidade de São Paulo - (HCFMUSP), São Paulo (SP), Brasil.
}

The authos declare no conflict of interest. 


\section{Cross-linking: an updated and effective insight}

Cross-linking (CXL) expresses the formation of chemical bonds after chemical reactions between proteins or other molecules. These reactions can be initiated by heat, pressure or radiation and can happen naturally in the human body ${ }^{(1)}$. Corneal cross-linking associated with riboflavin and ultraviolet light type A (UV-A) have been increasingly used for the treatment of ectatic corneal diseases.

Introduced in the $90 \mathrm{~s}$, corneal CXL is being developed at a level considered effective and safe $^{(2)}$ when certain criteria are met. CXL increases the biomechanical strength of the cornea and its effect is associated with the dose of UVA light and the concentration of riboflavin ${ }^{(3)}$.

Although its practice has been predominantly used for treatment and control of ectatic diseases (keratoconus and ectasia induced after refractive surgery), there are other indications in study, as for the treatment of infectious keratitis, corneal edema, pathological myopia, among others.

\section{Background}

The interaction of riboflavin with UV -A light produces reactive oxygen species that origin covalent bonds between collagen molecules, inducing corneal biomechanical stiffness. The photochemical effect of CXL occurs when the UV-A light, activates riboflavin. This method presents a localized, short- term effect, does not affect the transparency of the cornea and is safe for the lens and the retina.

Riboflavin, or vitamin B12, is hydrophilic ${ }^{(4)}$, thus it is more difficult to penetrate the corneal epithelium. Because of its nontoxic nature, riboflavin is essential for better biomechanical effects of CXL on corneal stroma. There are different methods for obtaining the optimal concentration of riboflavin in the stroma: 1) Diffusion in the corneal stroma after epithelium deepithelialization (Conventional CLX);2) stromal diffusion through the epithelium (Transepithelial method) or 3 ) direct introduction of the riboflavin into the stroma (stromal "pocket").

Currently "conventional" CXL is the technique most commonly performed worldwide, but there are other variations of this procedure such as accelerated CXL, Transepithelial CXL,Pediatric CXL, CXL combined with other procedures, among others ${ }^{(1,5)}$.

\section{Conventional CXL}

This variation, also called Dresden CXL (named after the group of Dresden, Germany, who studied a large number of patients undergoing CXL) is the most performed and most internationally widespread. It consists in applying CXL after corneal epithelium is removed. It uses $0.1 \%$ riboflavin every 1 to 2 minutes to 30 minutes for adequate penetration. After thirty initial minutes, the patient's eye is examined with blue light, confirming the presence of riboflavin in the anterior chamber (AC) so that the polymerization process can be initiated.

If there is the absence of riboflavin at this stage, the same solution should be instilled until its noticed in the anterior chamber.

Another important step is the confirmation of minimum corneal thickness of 400 microns, because even with the evidence that the CXL acts in the previous $2 / 3$ of the cornea, there is consensus that less than 400 microns thickness increases the risk of corneal endothelial damage. One way to achieve this minimum thickness is using $0.1 \%$ hypotonic riboflavin.

Confirming these prerequisites begins the irradiation with UV-A light associated with instillation of riboflavin every 2 to 5 minutes for 30 minutes. The UV-light has a power output of
$3 \mathrm{~mW} / \mathrm{cm} 2$ and within 30 minutes is reached the desired amount of energy for treatment, or $5.4 \mathrm{~J} / \mathrm{cm} 2$.

Postoperative resembles photorefractive keratectomy (PRK), with the use of eye drops topical antibiotics, hormonal and non-hormonal anti-inflammatory, associated with exhaustive use of lubricants.

\section{UVA Radiation}

The wavelength of the UV - A irradiation is approximately $370 \mathrm{~nm}$. This wavelength reaches the largest cross-linking effect. As Riboflavin has its maximum absorption at $365 \mathrm{~nm}$, its association with UV - A light was chosen.

Riboflavin concentration of $0.1 \%$ produces a high coefficient of absorption ${ }^{(6)}$ and $90 \%$ of the UV radiation is absorbed in the stroma, while the endothelium, the retina and the lens is protected from radiation.

Endothelial cytotoxicity occurs by UV -A dose of $3.6 \mathrm{~mW} /$ $\mathrm{cm} 2$. The actual dose that reaches the endothelium using the standard protocol is $1.8 \mathrm{~mW} / \mathrm{cm} 2$, which is half the toxic dose $\mathrm{e}^{(7)}$.

\section{Complications}

Although quite rare, the CXL procedure may cause some complications. Herpetic keratitis is one of the most common of them, especially if associated with a history of herpes, but not exclusively in those cases. Patients should be informed about the possibility of this complication and, in some cases, might receive topical and systemic antiviral medications after the procedure ${ }^{(1)}$.

Transient opacity is a relatively common side effect after CXL and reflects the corneal healing process. Very different from the post-PRK Haze, for though the latter presents a limitation in the subepithelial region, Haze induced CXL can affect up to $60 \%$ of the depth of estroma ${ }^{(8)}$. Solomon et al. published in 2011 a study showing that CXL is associated with increased apoptosis, followed by a regeneration process that would explain the momentary haze after treatment ${ }^{(9)}$. These authors also concluded that this transient effect has greater chance of occurring in corneas with keratometry greater than 54D.

Other possible complications include stromal scarring, diffuse lamellar keratitis (DLK), iritis (particularly when associated with herpes virus), endothelial cell loss (minimal loss, most of the time), among others.

Transient decrease in the innervation and corneal sensitivity can also occur, especially in the initial six months; as noted in the studies of Kontadakis et al. in 2013. In the same study was not observed effects on basal tear secretion nor the stability of the lacrimal film ${ }^{(10)}$.

\section{Transepitthelial CXL}

Since the continuous development and outputs of CXL removing the epithelium (conventional technique), other methods have been proposed to try to smooth patient discomfort and decrease the incidence of complications associated with the removal of the central corneal epithelium. One alternative would be to keep the whole epithelium and perform via Transepithelial CXL.

For better results, this technique uses aggregated substances that enhance the penetration of riboflavin in the corneal stroma such as the use of tetracaine or benzalkonium-ethylenediaminetetraacetic acid (BKC-EDTA). Both drugs reduce the barrier function of corneal epithelium, increasing the penetration of riboflavin in estroma ${ }^{(11)}$.

Although this technique presents some advantages, results are not presented as just as effective as convencional techinique ${ }^{(12)}$. 
Armstrong and colleagues showed in their studies in rabbits that the epithelium blocks the UVA light, contributing to the reduction of its efficacy ${ }^{(11)}$. No one knows for sure if the Transepithelial treatment will present long term efficacy, but studies report that it apparently interrupts the progress of keratoconus, however in a less pronounced manner than conventional CXL.

Its non -invasive nature expands its use in cases where the epithelial removal can be avoided such as in cases of ocular surface disorders, dry eyes, children, patients with poor adherence and patients with thin corneas ${ }^{(1)}$.

\section{"Pocket" CXL}

This technique consists of applying riboflavin directly into the stroma, also named direct application. A "pocket" is created in the stroma, and then filled with riboflavin to perform the corneal cross-linking. Currently this stromal pocket is being done with greater accuracy through the femtosecond laser. It is a promising technique and needs further investigation to become a routine treatment.

\section{Accelerated CXL}

This variation of the CXL (also named "fast CXL") has been studied with the intention to reduce the exposure to UVA light with higher radiation exposure. This is accomplished by removing the epithelium; however, CXL is performed for 3 minutes with UVA light at an irradiance of $30 \mathrm{~mW} / \mathrm{cm} 2$ (also resulting in a final amount of $5.4 \mathrm{~J} / \mathrm{cm} 2$ ). No consensus yet on its parameters, different protocols are being made with variations of values as 9 minutes with $10 \mathrm{~mW} / \mathrm{cm} 2,15$ minutes by $7 \mathrm{~mW} /$ $\mathrm{cm} 2$ among others ${ }^{(5,13)}$. Due to excessive irradiation it is suggested to use a shield in the limbus to protect stem cells ${ }^{(5,14,15)}$.

Studies have shown similar results between accelerated and conventional CXL, but longer durations segments are needed to confirm efficacy and safety of this procedure ${ }^{(5,13,14)}$.

\begin{tabular}{lcccc}
\hline Author & Year & $\begin{array}{c}\text { Intensity } \\
(\mathbf{m W} / \mathbf{c m} 2)\end{array}$ & $\begin{array}{c}\text { Treatment Time } \\
\text { (minutes) }\end{array}$ & $\begin{array}{c}\text { Dose } \\
(\mathbf{J} / \mathbf{c m})\end{array}$ \\
\hline Standard & - & 3 & 30 & 5,4 \\
Vega-Estrada A & 2012 & 30 & 3 & 5,4 \\
Touboul D & 2012 & 30 & 3 & 5,4 \\
Celik HU & 2012 & 30 & 3 & 5,4 \\
Schumacher S & 2011 & 10 & 9 & 5,4 \\
Kanellopoulos J & 2012 & 7 & 15 & 6,3 \\
\hline
\end{tabular}

Different Protocols in Accelerated CXL

\section{Pediatric CXL}

The pediatric patient with diagnosis of keratoconus carries an unfavorable prognosis of the disease and a higher probability of a future transplantation of the cornea. Many studies have demonstrated the ability of CXL in reducing the progression of keratoconus in pediatric patients ${ }^{(16-19)}$.

It is not mandatory to wait for the ectasia progression to start the CXL in children and most studies suggest not expect the progression and begin treatment as soon as the diagnosis is made. Arora et al. studied 15 young people aged between 10 and 15 years with keratoconus and underwent CXL; without evidence of progression after a follow-up of 12 months, recommend early treatment with CXL in young patients ${ }^{(16)}$. Chatzis and colleagues obtained similar results and propose the same recommendation at the end of their studies ${ }^{(19)}$.

Although Transepithelial CXL presents a great advantage in the use in children due to the less painful process, Buzzonetti et al. showed in their studies less efficiency with transepithelial mode, despite using an apparently low number (13 eyes) in their studies in 2012, and suggest that this method can be used as a supplement to conventional treatment process $^{(17)}$.

Another important aspect to consider is the importance of controlling other eye diseases in children, as evidenced by Arora et al. in 2012 with the report of the observation of sterile keratitis in a child with uncontrolled vernal keratoconjunctivitis that was submitted to $\mathrm{CXL}^{(20)}$.

Many studies still need to be made to achieve a consensus regarding treatment with CXL in pediatric patients, but early treatment apparently proves to be prosperous.

\section{Associations}

With the increasingly common use of CXL, new therapeutic options are being studied, associating the CXL with other procedures such as combination with other refractive procedures and/or intracorneal rings.

\section{Athens Protocol}

Same day topography-guided partial PRK and collagen cross-linking is proposed by Kanellopoulos et al. ${ }^{(21)}$, who believes that there is a synergistic effect when the procedures are performed simultaneously in patients with keratoconus and ectasia post LASIK cases. He also mentions that this would be a therapeutic and not refractive procedure, treating the irregularities of the corneal surface and improving the patient's vision. The protocol includes up to four steps:

1. Removal of the epithelium (diameter of $6.5 \mathrm{~mm}$ ) by phototherapeutic keratectomy (PTK);

2. Topography-guided partial photorefractive keratectomy (PRK) with maximum consumption of 50 microns of the stroma;

3. Application of mitomycin - C $0.02 \%$ for 20 seconds;

4. Corneal CXL technique ${ }^{(22)}$.

The Athens protocol has presented encouraging results ${ }^{(23)}$ and is also being undertaken worldwide ${ }^{(24)}$. In Saudi Arabia, the team Tuwairqi also studied the simultaneous procedure, and achieved good effects in patients with low grades keratoconus ${ }^{(23)}$.

\section{Tripletherapy}

The triple therapy consists in the association of the intra corneal ring (ICR) at the Athens protocol, in other words, it is postulated the use of intra-corneal ring, associated with corneal topography -guided PRK, together with the corneal CXL procedure $^{(25)}$. The purpose of this therapy would be to use the ICR to induce flattening of the cornea and reduce astigmatism, allowing treatment (PRK) guided by topography with minimal ablated tissue. Al-Tuwairq and colleagues concluded in their study with 13 eyes that triple therapy may be a safe and effective option in certain patients with keratoconus ${ }^{(25)}$. Kymionis et al. described the implantation of ICR with subsequent treatment by topography guided PRK associated with CXL in patients with pellucid marginal degeneration and his results also showed a significant improvement in visual acuity of patients ${ }^{(26)}$. 
Such therapies and associations are still in study ${ }^{(27)}$ and there is no consensus so far for the best way to be performed for patients with corneal ectasia, whether primary or secondary to surgical procedures .

\section{CXL applications in no ectatic diseases}

Although corneal CXL associated with riboflavin and UVA light forward acknowledgment for the treatment of corneal ectasia, its applications for non ectatic disorders are less known and applied, as in cases of corneal edema, infectious keratitis and other diseases.

Studies have been made and reported in the literature applying CLX in corneal edema and the results are showing improvement in patient's pain, decrease in central corneal thickness and improvement under edema ${ }^{(28)}$. However, more studies are needed to standardize this type of treatment.

Another reported application is the use of corneal CXL therapies in infectious keratitis and the results demonstrated better outcomes in bacterial keratitis than in fungal ${ }^{(29)}$. Nevertheless, further studies are necessary to evaluate the effectiveness of this modality.

Another promising study, presented, by Wang et al. ${ }^{(30)}$, suggests the use of scleral CXL to increase the biomechanical strength of the sclera and thereby to prevent progressive myopia. However, these are in vitro and still experimental studies.

\section{Conclusion}

Keratoconus and other corneal ectasia are diseases characterized by progressive corneal thinning that result in corneal protrusion, irregular astigmatism and decreased visual acuity. There are a variety of treatments that aim to resolve or alleviate the patient's problems as the use of glasses, soft and/or rigid gas permeable, intra-corneal rings and corneal transplant. All these mentioned therapies aimed at improving the consequences caused by the evolution of these pathologies.

Corneal CXL is the only procedure nowadays that aims to treat the biomechanics of the cornea and not only the consequences of corneal irregularity. It does not represent the ultimate cure for ectatic corneal diseases, but it is an effective procedure to halt its progression.

The collagen corneal CXL is already a reality in the treatment of corneal ectasia, however further studies and protocols should be made to standardize this procedure.

\section{References}

1. Raiskup F, Spoerl E. Corneal crosslinking with riboflavin and ultraviolet A. I. Principles and Part II. Clinical indications and results. Ocul Surf. 2013; 11(2): 65-74; 93-108.

2. O'Brart DPS, Kwong TQ, Patel P, McDonald RJ, O'Brart NA. Long-term follow up of riboflavin/ultraviolet A (370nm) corneal collagen cross-linking to halt the progression of keratoconus. Br J Ophthalmol. 2013; 97(4): 433-7.

3. Koller T, Schumacher S, Fankhauser II F, Seiler T. Riboflavin/ ultraviolet A crosslinking of the paracentral cornea. Cornea. 2013; 32(2): 165-8.

4. Malhotra C, Shetty R, Kumar RS, Veluri H, Nagaraj H, Shetty $\mathrm{KB}$. In vivo imaging of riboflavin penetration during collagen cross-linking with hand-held spectral domain optical coherence tomography. J Refract Surg. 2012; 28(11): 776-80.
5. Touboul D, Efron N, Smadja D, Praud D, Malet F, Colin J. Corneal confocal microscopy following conventional, tranepitelial, and accelerated corneal collagen cross-linking procedures for keratoconus. J Refract Surg. 2012; 28(11): 769-75.

6. Iseli HP, Popp M, Seiler T, Spoerl E, Mrochen M. Laboratory measurement of the absorption coefficient of riboflavin for ultraviolet light (365nm). J Refract Surg. 2011; 27(3): 195-201.

7. Bagga B, Pahuja S, Murthy S, Sangwan VS. Endothelial failure after collagen cross-linking with riboflavin and UV-A: case report with literature review. Cornea. 2012; 31(10): 1197-200.

8. Gutiérrez R, Lopez I, Villa-Collar C, González-Méijome JM. Corneal transparency after cross-linking for keratoconus: 1-year follow up. J Refract Surg. 2012; 28(11): 781-5.

9. Salomão MQ, Chaurasia SS, Sinha-Roy A, et al. Corneal wound healing after ultraviolet-A/riboflavin collagen cross-linking: a rabbit study. J Refract Surg. 2011; 27(6): 401-7.

10. Kontadakis GA, Kymionis GD, Kankariya VP, Pallikaris AI. Ophthalmology .2013; 120(5): 917-22.

11. Armstrong BK, Lin MP, Ford MR, Santhiago MR, Singh V, Grossman GH, Agrawal V, Roy AS, Butler RS, Dupps WJ, Wilson SE. Biological and biomechanical responses to traditional epithelium-off and transepithelial reiboflavin-UVA CXL techniques in rabbits. J Refract Surg. 2013; 29(5): 332-41.

12. Filippello M, Stagni E, ÓBrart D. Transepithelial corneal collagen crosslinking: bilateral study. J Cataract Refract Surg. 2012; 38(2): 283-91.

13. Celik HU, Alagoz N, Yildirim Y, Agca A, Marshall J, Demirok A, Yilmaz OF. Accelerated corneal crosslinking concurrent with laser in situ keratomileusis. J Cataract Refract Surg. 2012; 38(8): 1424-31.

14. Vega-Estrada A, Alió JL, Puche ABP, Marshall J. Outcomes of a new microwave procedure followed by accelerated cross-linking for the treatment of keratoconus: a pilot study. J Refract Surg. 2012; 28(11): 787-92.

15. Gore DM, Shortt AJ, Allan BD. New clinical pathways for keratoconus. Eye (Lond). 2013; 27(3): 329-39.

16. Arora R, Gupta D, Goyal JL, Jain P. Results of corneal collagen cross-linking in pediatric patients. J Refract Surg. 2012; 28(11): 759-762

17. Buzzonetti L, Petrocelli G. Transepithelial corneal cross-linking in pediatric patients: early results. J Refract Surg. 2012; 28(11): 763-7.

18. Zotta PG, Moschou KA, Diakonis VF, Kymionis GD, Almaliotis DD, Karamitsos AP, Karampatakis VE. Corneal collagen crosslinking for progressive keratoconus in pediatric patients: a feasibility study. J Refract Surg. 2012; 28(11): 793-6.

19. Chatzis N, Hafezi F. Progression of keratoconus and efficacy of pediatric corneal collagen cross-linking in children and adolescents. J Refract Surg. 2012; 28(11): 753-8.

20. Arora R, Jain P, Gupta D, Goyal JL. Sterile keratitis after corneal collagen crosslinking in a child. Cont Lens Anterior Eye. 2012; 35(5): 233-5.

21. Kanellopoulos AJ. Combining topography-guided PRK with CXL: the Athens protocol. Cataract Refract Surg Today Euro. 2010; 18-21.

22. Kanellopoulos AJ. The Athens protocol. Cataract Refract Surg Today. 2011; 31-4.

23. Tuwairqi WS, Sinjab MM. Safety and efficacy of simultaneous corneal collagen cross-linking with topography-guided PRK in managing low-grade keratoconus: 1-year follow-up. J Refract Surg. 2012; 28(5): 341-5. 
24. Alessio G, L'abbate M, Sborgia C, Tegola MG. Photorefractive keratectomy followed by cross-linking versus cross-linking alone for management of progressive keratoconus: two years follow up. Am J Ophthalmol. 2013; 155(1):54-65e.1.

25. Al-Tuwairqi W, Sinjab MM. Intracorneal ring segments implantation followed by same-day topography-guided PRK and corneal collagen CXL in low to moderate keratoconus. J Refract Surg. 2013; 29(1): 59-63.

26. Kymionis GD, Grentzelos MA, Portaliou DM, Karavitaki AE, Krasia MS, Dranidis GK, Kozobolis VP.Photorefractive keratectomy followed by same Day corneal crosslinking after intrastromal corneal ring segment implantation for pellucid marginal degeneration. J Cataract Refract Surg. 2010; 36(10): 1783-5.

27. Coskunseven E, Jankov MR, Grentzelos MA, Plaka AD, Limnopoulou AN, Kymionis GD. Topography-guided transepithelial PRK after intracorneal ring segments implantation and corneal collagen CXL in a three-stepprocedure for keratoconus. J Refract Surg. 2013; 29(1): 54-8.
28. Bettis DI, Hsu M, Moshirfar M. Corneal collagen cross-linking for nonectatic disorders: a systematic review. J Refract Surg. 2012; 28(11): 798-807.

29. Price MO, Tenkman LR, Schrier A, Fairchild KM, Trokel SL, Price FW. Photoactivated riboflavin treatment of infectious keratitis using collagen cross-linking technology. J Refract Surg. 2012; 28(10): 706-13.

30. Wang M, Zhang F, Qian X, Zhao X. Regional biomechanical properties of human sclera after cross-linking by riboflavin/ultraviolet A. J Refract Surg. 2012; 28(10): 723-8.

\section{Corresponding author:}

Roberto N. C. Horovitz 